\title{
The Development of the Competencies Linked to the Human Dimension of Engineering
}

\author{
Richard Thibault, Noêl Boutin, Danielle L'Heureux, René Hivon
}

\author{
Université de Sherbrooke
}

\begin{abstract}
This article describes how a group of faculty members at the School of Engineering, Université de Sherbrooke, Canada, are going about implementing a novel and fully integrated approach to developing in engineering undergraduate students the competencies linked to the human dimension of engineering. First, a critical and skeptical eye is being used to describe and assess the results of the traditional modus operandi coined "the two solitudes": "soft" courses taught by non-engineers on one part, and technical courses taught by engineering professors who are illequipped to dwelve to any meaningful depth in such topics as ethics, team work, communication, leadership, creativity, critical thinking, engineering management, etc. on the other part. This article then describes how, after an exhaustive survey of the literature, a grant from the University's Major Pedagogical Innovations Program is being used to devise ways in which the development of the interpersonal and intrapersonal competencies of engineering students will be intimately integrated throughout the whole undergraduate programs with that of the scientific and technical competencies. This entire process is under the responsibility of engineering professors. In order for this ambitious goal to be achieved, the group of faculty put together a strategic plan based on the professional aspects of engineering practice and which calls for five separate but complementary courses of action: a continuous technology watch, a research program, the design of appropriate pedagogical material, the training of engineering professors in the use of this material, the online classroom use of same material and, lastly, the publication of results. The article ends with an analysis of the results achieved so far and an optimistic look at the future that this novel approach allows to envisage.
\end{abstract}

Key words: integrated curriculum, human dimension of engineering, soft skills, competencebased curriculum 


\section{Introduction}

For many years, engineering accreditation bodies ${ }^{1}$ have required engineering curricula to have a minimum proportion of their content devoted to the development of "soft skills" or to complementary studies. This not only gives engineering students a broader education but it enables them to import from the humanities and the social sciences tools, methods and mental processes that allow holistic approaches to engineering problems and that are very likely to be conducive to better engineering solutions.

The way engineering schools have discharged their responsability with respect to those accreditation guidelines that are related to complementary studies varies immensely from one institution to another. But the most frequent avenue is, on the one hand, having the complementary courses taught by good or even reknowned specialists in psychology, sociology, law, ..., who are not engineers and whose knowledge about engineering is sometime limited and, on the other hand, having the science and technology courses taught by engineers whose primary concern seems at times to be to dispense to their students as much technical knowledge as possible and for whom the technical expertise of the students is seldom high enough. ${ }^{2}$

The typical situation described in the preceding paragraph has advantages, the main ones being that: a) courses in the complementary studies are being taught by people who have a meaningful expertise in their fields (psychology, sociology, law, ...); b) this exposure to professors who are not engineers give students the opportunity to see in a first-hand manner the way non-engineers solve their problems and to transpose to engineering problems the tools used by specialists in social sciences and humanities (as required by the CEAB guidelines ${ }^{3}$ ).

However, the other side of the balance sheet is a little longer and it is the authors' view that it may be heavier than the first one in terms of the negative influence it may have on the quality of education engineering students get.

Firstly, by having two sets of professors (the non engineers and the engineers) and two sets of courses (the complementary studies and the science/technology courses), the teaching is offered in a compartmentalized way and students develop two sets of competencies that do not mingle, that are not integrated. This is what we, at Sherbrooke, call the "two solitudes". This fact is in line with the findings of Al-Holou et al [1].

1 Accreditation Board for Engineering and Technology (ABET) in the United States and Canadian Engineering Accreditation Board (CEAB) in Canada.

2 To be fair, it is essential that one widely spread exception be noted here: very often, the course in engineering economics imposed to Canadian engineering schools by the CEAB is taught by engineering professors. However, it is also to be mentioned that the expertise students develop in this course is seldom used in other courses except, perhaps, in design courses or projects.

Contrary to ABET requirements which are based on a programme's outcome, CEAB requirements are linked to the process, to the programmes themselves. According to $\mathrm{CEAB}$, engineering programmes must include a minimum of $18000 \mathrm{AU}$ (accreditation units) and this number is broken down as follows: mathematics (195 $\mathrm{AU}$ ), basic sciences (225 AU), engineering sciences and engineering design (minimum total of $900 \mathrm{AU}$ and a minimun of $225 \mathrm{AU}$ for each), complementary studies (225 AU) which leaves $255 \mathrm{AU}$ to be used as seen fit by each school. Complementary studies comprise humanities, social sciences, arts, management, engineering economics and communication. 
Secondly, after having completed a certain number of science/technology courses without having heard their professors who are engineers talk about the human aspects of engineering (ethics, communications, team work, creativity, ...), students tend (consciously or not) to develop a belief that engineering is nothing but a mixture of science and technology and that complementary studies are just a necessary evil to get easier access to professional recognition upon graduation. ${ }^{4}$

Thirdly, in supporting the two solitudes, or even in allowing it to exist, engineering schools give students a wrong signal, a somewhat distorted view of engineering in which ethics seems to have no bearing on design, creativity has no impact on problem solving, and team work has no impact on the quality of the work performed. In a way, it is as if engineering schools sometimes gave their students the implicit message that it is possible for engineers to work on ethics one day, to work in teams the next day and to communicate the following day.

Fourthly, because of their distorted view of engineering, third- and fourth-year students develop a deeper and deeper craving for more technical courses and they are under the impression that it is their last chance to get a better (technical) education before entering the labor market.

Finally, engineering professors are quite content to restrict themselves to the technical aspects of engineering and to better their undergraduate teaching by importing elements from their research work...and this satisfaction tends not to urge them to incorporate non technical components to their technical courses.

This article will provide a brief overview of what some engineering schools have done to improve the education of their engineering students in the areas covered by the complementary studies and it will provide a detailed description of how similar attempts at the Universite de Sherbrooke have led to rather original results, in particular, the creation of an Institute (or Group) for the Human Dimension of Engineering ${ }^{5}$. Using a competency-based approach, the Institute strives for an added value to the engineering education by integrating in science/technology courses the development of those competencies linked to the human dimension of engineering. It must be pointed out at the beginning of this article that competencies linked to the human dimension of engineering include all the competencies that are not scientific or technological in nature and that engineers need to master to have a fruitful career. As this article will later show, these competencies can be classified into nine categories: communication, ethics, teamwork, leadership, creativity, responsibility, critical thinking, social implication and management.

$4 \quad$ To be allowed to practice engineering in a Canadian province, a person must first seek membership in the Order of Professional Engineers of that province. All provincial Orders of Professional Engineers have given the Canadian Council of Professional Engineers the mandate to create within its structure the CEAB that would manage the accreditation process on a Canada-wide basis.

$5 \quad$ The mission and the plan of action put forward by that group of professors have been accepted and funded but the permission to build the structure of the Institute has not been granted yet. In this article, the words Institute or Group will be used indifferently.

Proceedings of the 2002 American Society for Engineering Education Annual Conference \& Exposition Copyright $($ 2002, American Society for Engineering Education 


\section{Significant efforts to change the traditional approach}

Notwithstanding the previous section, it is not to say that engineering schools throughout the world have done nothing to get away from the traditional "two-solitudes" approach. This section first briefly describes what has been done at various engineering schools then sharply focuses on the Université de Sherbrooke.

\subsection{Specific actions to integrate soft skills in engineering curricula}

The last decade has seen the birth of a wide variety of experiments, some of them being carried out by one faculty who wished to integrate the development of one specific "soft" competency to one of his science/technology course, others being much larger in magnitude and scope, and bringing together a large numbers of faculty and involving more than one course. Some examples are given in the following paragraphs.

In Sweden, Johansson and Ohlsson [2] have created a two-year software engineering education program at Kalskrona/Ronneby University College where they have included professionalism as a major educational element. As the basis for teaching professionalism, they use the concept of commitment culture, a working atmosphere built on voluntarily taking responsibility. A large proportion of the curriculum consists of project courses, which are run as role-playing games where teachers act as customers and consultants.

In the United States, Seat and Lord [3] have developed a program for teaching interaction skills to engineers and engineering students. It uses the typical engineer's problem solving strengths to teach skills of interviewing, questioning, exchanging ideas and managing conflict.

From Michigan State University, Gunn [4] describes a freshmen experience aimed at building an attitude that senses the need for a team effort in engineering, the attributes of a successful team member being creativity, willingness to listen, speak and question, follow through, responsibility, aptitude to work and leadership qualities but ability to follow.

At Purdue University, Wankat et al describe [5] how the soft criteria have been integrated into the Chemical Engineering curriculum. They indicate how they were successful in integrating communication skills, how they feel they have done a more than adequate job in integrating team work and learning to learn skills, why they think they have done an adequate job in integrating ethical behavior and why they think an increased effort is still needed to integrate the other two ABET criteria (lifelong learning and knowledge of temporary issues). Finally, they conclude from a survey of practicing engineers that laboratory, design work and practical work experience are the most important sources for learning to satisfy the soft criteria.

At the University of Minnesota, Smith gives [6] various strategies to develop engineering student's teamwork and project management skills while Clarke et al show [7] how they have developed a course that fully integrates instruction in both history and materials science. 
On a different level, Mello shows [8] how Worcester Polytechnic Institute's project-based curriculum allows students to complete professional-level projects at remote locations thus solving real-world problems while being immersed in a different culture.

The Franklin W. Olin College of Engineering [9] is an entirely new institution. They have developed a curriculum for the new millennium in collaboration with the National Science Foundation (NSF), the American Society for Engineering Education and ABET. The emphasis will be on providing a rigorous preparation in engineering science, team-based design, communications, independent projects and research, and principles of business management and entrepreneurship. The abilities they would like to see their graduates master are:

- Rigorous background in engineering science;

- Broad base in liberal arts, writing and communication;

- Superior computational skills;

- Experience in small team project design and project based problem solving;

- Exposure to cutting edge research activity in corporate and university settings;

- Firsthand knowledge of business and entrepreneurial practices;

- Philanthropic spirit;

- Confidence.

In Canada, McMaster University has implemented the Problem-based learning (PBL) approach conceived by Woods $(1993,1996)$ [10]. PBL is a generic term. According to Woods, «PBL.... is one of the most exciting and powerful educational options that has appeared in the last 30 years.»> Forms of PBL that have been used include research, Case Studies, Guided Design, engineering design projects and the McMaster Medical School model of PBL. Some forms can be used for large classes, some for small groups and some for intermediate sizes.

Finally, there is the case of the NSF coalitions. A broad consensus between employers, educators, government and ABET has developed with respect to the need to bring changes to engineering education. Various initiatives have allowed the emergence of a new vision of the engineer and of the way to train him or her. NSF has fostered the creation of many coalitions of university campuses and institutes called Engineering Education Coalitions...the main objectives of these being to stimulate the reform of the teaching/training models by developing pedagogical tools, curricula and innovative systems. NSF has supported the creation of eight engineering education coalitions: Ecsel, Synthesis, Gateway, SUCCEED, Foundation, Greenfield, Academy and SCCEME.

The NSF has formulated its vision in the following words:

"Employers emphasize that success as an engineer increasingly requires, in addition to strong technical capability, skills in communication and persuasion, ability to lead and work effectively as a member of a team, understanding of the non-technical forces that profoundly affect engineering decisions, and a commitment to lifelong learning... Acquiring such characteristics is unlikely with traditional, lecture-based instruction. A new 
engineering education paradigm is needed, characterized by active, project

based learning; horizontal and vertical integration subject matter;

introduction of mathematical and scientific concepts in the context of

application; close interaction with industry; broad use of information

technology; and a faculty devoted to developing emerging professionals as mentors and coaches. ",

\section{NSF Foundation Coalition}

One of the first initiatives, the NSF Foundation Coalition was founded on October 1, 1993. Regrouping seven universities and institutes, this coalition was aiming at becoming a leader in the implementation of the new culture in engineering education. Its broad strategic objectives and deliverables are the following ${ }^{7}$ :

- Responsive Curricula: Offer new curricula that incorporate cooperative learning, curriculum integration and technology; that respond to the mission and students of the institution; and that can adapt to the changing needs of society;

- Inclusive learning Communities: Organize and assess inclusive learning communities - group of students, faculty, employers who value diversity and work as partners to improve the engineering educational experience;

- Assessment and Evaluation Processes and Procedures: Assess and evaluate the effectiveness of the innovations developed;

- Models for the Management and Institutionalization of Change: Formally document new models for facilitating curricular change;

- Sharing with the Engineering Education Community: Assist affiliated campuses in transferring curriculum models and others innovations to their campus.

Even though the partners in this coalition share the same vision, their actions are in line with the culture of each of the various schools. Members of this coalition are: Arizona State University, Maricopa Community College District, Rose-Hulman Institute of Technology, Texas A\&M University-Colege Station, Texas A\&M University-Kingsville, Texas Woman's University and University of Alabama. Five years after the creation of the coalition, the partners have assessed their achievements. The quality of their innovations has allowed them to pursue their course of action for four more years with the help of NSF. They had targeted eight specific objectives and these have been achieved. Among them, we have the following:

- Freshman Curricula: At each partner institution they have created viable freshman curricula and learning environments based on the four primary thrusts of the Coalition;

- Sophomore Curricula: At each partner institution they have created viable sophomore curricula and learning environments bases on the four primary thrusts of the Coalition. 
Since 1993, other members have joined this coalition, which still aims as being the leader in the creation of a new culture in engineering education. They wish to extend their vision to the whole of the engineering school community.

\section{$\underline{\text { SUCCEED (Southeastern University and College Coalition for Engineering Education) }}$}

This second coalition of eight campuses was set up in 1992 with the financial help of NSF. As was the case for the Foundation Coalition, the SUCCEED partners aim at bettering engineering education practices, reforming curricula using a holistic approach.

In December 2001, SUCCEED $^{8}$ published the results of a survey to which each partner participated. Their conclusion was, among others, that success calls for:

- Nontraditional instructional methods;

- Technology-assisted instruction;

- Participation in and effectiveness of faculty development programmes;

- Teaching quality and innovation.

\section{Gateway Coalition}

This is a collaborative program of seven institutions. The strategic plan of the Gateway Coalition is based on the six following elements:

- The central focus is the development of students as emerging professionals;

- The retention of students;

- Changing how we teach uses approaches that are appropriate for learning the content, skills, and competencies the student needs;

- The structure of curriculum can impact both what is taught and how it is taught and is a major descriptor of the educational program;

- Facilitating the implementation and institutionalization of innovation in engineering education is a potential role for the coalition;

- Developing relationships among Gateway institutions.

\section{$\underline{\text { Synthesis Coalition }}$}

Synthesis Coalition is a union of eight diverse institutions. This group was founded by the National Science Foundation to design, implement and assess new approaches to undergraduate engineering education that emphasize multidisciplinary synthesis, teamwork and communication, hands-on and laboratory experiences, open-ended problem formulation and solving, and examples of best practices from industry. 


\subsection{Université de Sherbrooke}

The Engineering School at Sherbrooke has a total of 1354 full time equivalent undergraduate students (FTES) and an overall enrolment of FTES. It offers 5 undergraduate co-op programmes, a Master of Engineering Management programme (in which over 300 people are registered), 4 M.Ap.Sc. and 4 Ph.D. programmes. Two additional undergraduate co-op programmes will be offered shortly (microelectronics and bioengineering).

Two of the authors have had a long implication (30 years in one case and 15 in the other) in trying to better the complementary studies portion of the undergraduate programs offered by their school.

Since 1970, the following avenues were investigated:

a) The objectives and contents of the complementary studies courses were defined jointly by our engineering school and some experts in other fields who held positions in other faculties. This approach was dropped after a few years for two main reasons:

- Professors from other faculties had a hard time dealing with the notion that it was possible to give an engineering student a worthwhile educational supplement by having him or her take only one course in any one subject;

- Although the course contents had been agreed upon by our school and each of the other faculties, they tented, with time, to drift back to those of courses given by the other faculties to their own students and became less and less engineering-students oriented;

b) We urged our students to take courses in other faculties, those courses being also taken by students from those other faculties. At the time, this approach was viewed as being ideal in the sense that it provided our engineering students with an opportunity to immerse themselves in a completely different environment and to better their education by mingling with students with totally different backgrounds and objectives. Again this approach had to be discarded because of the following reasons:

- Timetable conflicts were severe enough to limit the extent to which our students could prevail themselves of this opportunity;

- These courses having been designed to meet the needs of non-engineering students who would take sometimes three or four courses in any area, their contents were not always relevant to engineering students;

c) In the late $80 \mathrm{~s}$, our school created a tenure-tracked position, which was to be filled by someone holding a degree in one area of the human sciences, and this person was to be responsible for the whole of our complementary studies. We hired a person with a master's degree in psychology but he submitted his resignation after less than two years because he felt he couldn't achieve the objectives he had identified upon his hiring and because the job had not brought him the gratifications he had rightfully been looking for; 
d) In the early $90 \mathrm{~s}$, our school decided to try something new in that it signed agreements with other faculties whereby they would provide one professor who would be responsible for each of our complementary studies courses. As often as possible, that person would teach the course he or she was responsible for and, should he or she be unable to teach the course himself or herself, he or she would act as coach to the person actually teaching it. These agreements went as far as having professors from other faculties do all their teaching loads in our school (in return for the reimbursement of their salaries to the faculties they belonged to). Again, that approach was dropped because it developed the same symptoms as the others or because when a particular professor retired, no one having the same expertise could be identified.

So, at the end of the 90 s, after some 20 years of experimentation with different approaches, our school was nowhere nearer to a happy solution. The two solitudes still existed and we were still debating how we could do away with it.

\section{The Institute for the Human Dimension of Engineering}

In 1999, the two authors who are engineers sat down and compared notes as to why their school was not doing a better job than it was in the area of complementary studies. Their findings included the following elements:

a) In trying to develop those competencies linked to the human dimension of engineering, the school had so far totally relied upon courses that had been entirely dedicated to this objectives and which had had no or very few links to engineering practice;

b) Those courses had always been taught by specialists who had no or little knowledge of engineering practice;

c) Continuity among the professors responsible for the complementary studies courses was a major problem due to a high turnover rate of instructors;

d) The professors who held engineering degrees very seldom (if at all) talked about the links between their scientific/technological courses and the complementary studies courses;

e) The strategy for educating future engineers was based on a "course approach" as compared to a "programme approach" and the notion of teamwork between professors involved with the same groups of students during a particular semester was non existant.

These two professors decided to try to change things about and formed a group, which, it is hoped, will become the Institute for the Human Dimension of Engineering. They submitted a proposal to the vice-rector for undergraduate studies and received funding for the project described below. Though the work to be done has been funded, the permission for creating the Institute has not yet been granted. 
The ultimate goal of the Institute ${ }^{9}$ is to give an added value to the education of future engineers and its mission statement is the following:

"To facilitate the integration of the human dimension of engineering to the education and to the professional practice of engineers."

Taking into account the five elements listed at the beginning of this section and the additional fact that the solutions to the problems engineers are facing daily in their professional practice have simultaneous components of science, technology, ethics, communication, etc., it is believed that engineering education should simultaneously address these same components.

In other words, it is the contention of the Group that the two solitudes mentioned in section 1 must be eradicated and that, as they are used in real professional life, the competencies linked to the human dimension of engineering must be developed simultaneously with the competencies associated with science and technology. The simultaneousness referred to in this last sentence has a multi-faceted meaning: scientific/ technological competencies will be developed at the same time (in the same courses and by the same professors) as competencies linked to the human dimension of engineering. Such an objective is quite ambitious and could not be reached without a meaningful change in the culture of the school.

To bring about this change in culture and to achieve its mission, the Institute has identified five areas of action:

i. "Technological" watch: a constant monitoring of the media to detect new tendencies in the area of the human dimension of engineering, the measurement of the importance of these new tendencies in the engineering professional practice and the identification of groups or of organizations pursuing objectives similar to those of the Institute and with which the Institute could negociate and conclude strategic alliances;

ii. Research: the acquisition of new knowledge pertaining to the engineering school clientele, the measure of the students' perception of the nature of engineering practice and of the importance of the human dimension of engineering, the identification of optimal strategies to harmoniously integrate to engineering education and to professional practice the competencies linked to the human dimension of engineering;

iii. Competency development: development of the professors' and of the students' competencies linked to the human dimension of engineering;

iv. Development of relevant pedagogical material: development of material to be used by professors, in their "technical courses", to develop the students' competencies linked to the human dimension of engineering;

v. Publication: publication of the results of the Institute's work via articles, oral presentations and various other means so that any positive result happening at Sherbrooke could be disseminated throughout the entire engineering schools network. 


\section{Work done and work in progress at the Institute}

Upon its creation, the Institute (or the Group) for the Human Dimension of Engineering had many urgent things to do and this section describes what has been done so far and what falls under work in progress.

\subsection{Obtaining visibility/credibility within the School and proposing a new paradigm}

The ideas leading to the creation of the Institute (Group), described in section 3, had been favorably received by the School of engineering's Academic Council and by the Vice-rector (academic affairs), but the Institute for the Human Dimension of Engineering had no visibility, no authority and no real power (the power residing with the Undergraduate Programme Committees). Those elements had to be gained by offering professors and departments a stimulating and coherent plan of action.

The first project conducted by the Institute (and it is still ongoing) was to prepare a document telling the community what the Institute is, what it's mission and goals are, and outlining a plan of action that spells out how those goals could be reached for the benefit of all parties involved.

The part about the mission and goals was easy because it had been written many times to get support from the School Academic Council and the Vice-rector (academic affairs). The real challenge was to find a convincing way to tell faculty members how the Institute could prove to be a key actor in improving undergraduate programmes. Since the Institute was made up of only four people, it was deemed wise not to draw, for each programme, a list of those competencies linked to the human dimension of engineering and in the development of which the Institute would very actively participate. Instead, a unique list of competencies was prepared because an analysis of the objectives of the five undergraduate programmes showed that such a unique list would meet roughly $95 \%$ of the needs of all programmes.

This unique list of competencies is nearing completion and it has nine components: communication, ethics, responsibility, social implication, teamwork, creativity, critical thinking, leadership and management... and under each component, a set of competencies is being prepared. Figure 1 shows the interrelations between these areas of competencies linked to the human dimension of engineering, the competencies linked to science and technology and the two processes most-often used by practicing engineers (problem-solving process and design process). It is to be noted that two areas of competencies, communication and ethics, have a special status in the sense that they are so overwhelmingly present in professional practice that they are seen as metacompetencies.

This work in not done on the sole basis of our undergraduate programmes' objectives. It also draws on various documents published by the Ordre des Ingénieurs du Québec and on discussions within focus groups to which we periodically invite practicing engineers. We feel that this validation by practicing engineers adds credibility to our work. 


\subsection{Complementing the Institute's workforce}

One of the best ways to increase the number of people working toward the achievement of the Institute's goals is to call upon students. The authors have thought of various ways in which this can be done and the first they have actually used is to have students in the professional Master in Orientation programme of the Faculty of Education doing their essays on topics related to the Institute's mission and goals.

At present, a total of six such students are involved and the titles of their essays are the following: a) Reasons for choosing engineering as a career (male students, Université de Sherbrooke); b) Reasons for choosing engineering as a career (female students, Université de Sherbrooke; c) Reasons for dropping out of engineering (male and female students, Université de Sherbrooke); d) Peer training for the $1^{\text {st }}$ co-op work term; e) College students' representations of the engineering profession; f) Role of faculty members as models for engineering students. It is expected that the first essay to be completed will be so in late winter 2002 .

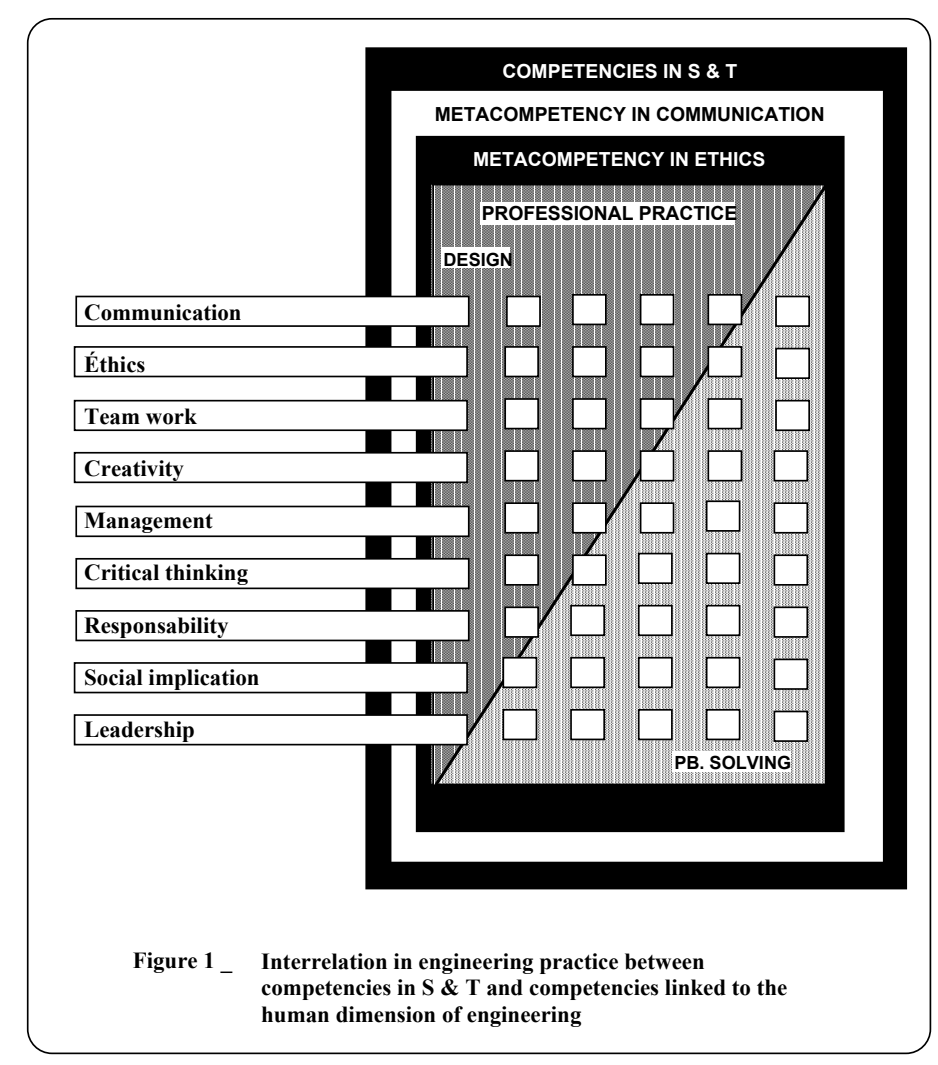

\subsection{Research project}

Before the Institute can tackle the design of pedagogical material to be used in scientific/technological courses to develop competencies linked to the human dimension of engineering, it has to know how this integration will be received by students, how important these competencies appear to be to students. 
With this objective in mind, a research project was launched and its purpose is to measure the students' perception of the importance, in their future professional practice, of the competencies linked to the human dimension of engineering. With the help of two people holding a Ph.D. in Education (orientation), a questionnaire was designed, pre-tested and it will be administered to all engineering students in the Fall of 2002. Not only will the results show the importance of those competencies in the students' minds but it will also show if this importance evolves as students progress in their programmes. Finally, if this questionnaire is administered every year, it will provide a measure of the effectiveness of the approach used by the Institute. Results of this project will be published as soon as they become available.

\subsection{Preparation of students for their first co-op work term}

Again with the help of a master's degree student from the Faculty of Education, training sessions for those students who were soon to leave on their first co-op work term were set up in the fall of 2001. The issues that these sessions dealt with were closely correlated to the competencies linked to the human dimension of engineering and they complemented in a nice fashion the sessions managed by the Coordination Service in charge of the co-op system.

The success of these training was such that the Institute has gone one notch further. During the winter of 2002, students in their final year are being trained (on a voluntary basis) to, in turn, become trainers for the students going on their first co-op work term during the summer of 2002. We feel this second approach is likely to yield even better results because of the following:

- Final-year students have a very high level of credibility in the eyes of $1^{\text {st }}$-year students because they have completed their four work terms and they will soon become engineers;

- Final-year students have gone through what $1^{\text {st }}$-year students are experiencing and they can easily share and identify with them.

Further more, we are facing a win-win situation: $1^{\text {st }}$-year students learn to know themselves better and identify the competencies that are required in the workplace and final-year students develop their competencies in team work and in social implication.

\subsection{Design and in-class use of pedagogical material}

It was planned that the development of pedagogical material would start in the fall of 2002 but this date was brought forward for two reasons: a) the Department of Electrical Engineering and Computer Engineering started implementing its two newly-revised undergraduate programmes in September $2001^{10}$ [12], [13] and, since they are competency-based and use a problem-based and project-based learning approach, some ways had to be found to incorporate to the new learning environment the development of the competencies linked to the human dimension of engineering; b) two of the authors (the two members of the Institute who hold an engineering

10 The implementation of the two new programmes will be gradually phased in and only the first-year students were involved in the fall of 2001 .

Proceedings of the 2002 American Society for Engineering Education Annual Conference \& Exposition Copyright (C) 2002, American Society for Engineering Education 
degree) belong to that department and they had been chosen to be part of the team responsible for the implementation of the new programmes. In short, the Department of Electrical Engineering and Computer Engineering provided the Institute with its first opportunity to develop pedagogical material. Even though this opportunity came one year ahead of schedule, it was too good to be missed.

In these new programmes, there is no such thing as lectures. The squeleton of these programmes is a series of megaproblems (students having to solve one every two weeks) and a design project spread over the entire semester. These two types of activities are complemented by laboratory work, problem-solving sessions and specialized workshops (stress management, resistance to change, learning strategies, concept mapping, ...).

Apart from what was needed for the specialized workshops, the material developed concerned mainly the megaproblems and the design project. Each megaproblem was basically science/technology oriented but it had to contribute to the development of some predetermined competencies linked to the human dimension of engineering. Some examples of megaproblems are the following:

- $\quad 1^{\text {st }}$ semester (electronics and engineering economics): Students were asked to explain how a given electronic circuit worked and to calculate the value of each of its components. Since the circuit was to be used to measure the exact value of resistors manufactured by a company (so as to be able to discard the resistors whose values did not fall within the advertised accuracy), students had to calculate by how much the company would have to increase the sale price of its resistors so that the initial investment in building de circuit would have in internal rate of return of $8 \%$;

- $\quad 1^{\text {st }}$ semester (software design and ethics): A co-op student, on his first work term, was asked to finish the design of a software started by another employee who had taken sick and had not documented his work.. This student had to find answers to the following questions: "Am I competent to do this work?", "Should I let my supervisor know about my doubts?", "Would it be better for me to start from the very beginning and ignore what has already been done or try to understand the part done by the other employee and build on it?", "My supervisor is not an engineer and he has assigned no engineer to supervise my design work. Is this an acceptable situation?"... "Whom can I go to and find out what I ought to do?";

- $\quad 2^{\text {nd }}$ semester (circuits and ethics): Students had to analyse issues related to intellectual property: the use of portions of a circuit designed by others;

- $\quad 2^{\text {nd }}$ semester (circuit design and engineering economics): Students had to design a circuit and, by analyzing the balance sheets of various suppliers, choose the supplier whose short and long term financial position was the best.

Globally, the pedagogical material developed and integrated in the megaproblems aimed at developing the competencies in written communication, teamwork and engineering economics.

Faculty are so used to writing problems having only science and technology components that each problem had to be written many times and each version was commented upon by the other 
members of the "1st-semester teaching team". When a version was nearing its final form, training sessions were held under the supervision of a professor from the Faculty of Education who acted as a consultant to both the Institute and the Department. During these sessions, each member of the teaching team, in turn, played the role of the tutor and the rest of the team played the role of the students that the tutor would meet during 90-minute weekly tutorial sessions during the semester.

On the other hand, the design project aimed at developing the competencies in oral and written communication, teamwork, creativity and project management. The material developed comprised the following: list of deliverables for the entire semester, steps of the design process, standards for writing the report of a design project, grids for evaluating oral presentations and written documents, tools of team work (communication within a team, planning, work distribution, conflict resolution, decision making, team consolidation, how to give feedback to a team member, grids for evaluating the efficiency of a team, ...), and how to plan participating in a commercial fair.

Two other elements deserve to be mentioned here. Student design teams (eight students to a team) had to keep a log book in which they were to note every detail relevant to their projects and each student had a learning journal in which he was supposed to write about his learning strategies. Throughout the semester, tutors kept reminding students to use these two tools since they would prove valuable when writing the design project report and the final exams. Those teams and students who did not heed this advice admitted at the end of the semester that they had really missed an excellent opportunity to work more efficiently. More on the learning journal can be found in Boutin [14].

All in all, this first try at developing pedagogical material proved to be very time-consuming but also very rewarding. At the end of the semester, many students told the authors how much they appreciated having to solve real-world or multi-faceted problems and acknowledged the amount of work it must have taken them to prepare the material. This came as no surprise to the authors since all through the semester they had received similar comments during debriefing periods to which each team sent a representative and which were held each second Friday.

\section{Conclusion}

At the Université de Sherbrooke's School of Engineering, a group of faculty set out to integrate to science/technology courses the development of the competencies linked to the human dimension of engineering. Ultimately, this integration would render the complementary studies courses redundant and these could therefore be done away with.

So far, their work has proven that this could be done in the first semester in two newly-revised Electrical Engineering and Computer Engineering programs using the problem-based and project-based approach. During the 2002 Winter semester, a similar undertaking is taking place in the second semester of the first year.

This integration work has necessitated an enormous amount of work but the results are very encouraging: a) students have openly and frequently said how much they appreciated solving 
real-world problems and conducting real-world design projects, namely problems and projects that bring out aspects of engineering practice that are not solely scientific or technological in nature; b) as a result of a), student motivation has increased and preliminary results show that the number of dropouts during the first semester has decreased with respect to preceding years; c) as soon as students set foot in the school, they start learning what engineering is all about and consequently, get a chance to confirm their professional orientation sooner that in a traditional curriculum.

It seems proper to point out a few of the factors that seem to be prerequisites for such an innovation to be successful. Firstly, the authors think that achieving the objective of simultaneously developing, in science/technology courses, the competencies linked to science and technology and those linked to the human dimension of engineering is almost impossible if a course approach is used. A programme approach offers so many more opportunities that it seems a must. Secondly, the authors firmly believe that the achievement of that same objective could hardly materialize if all faculty involved with teaching to a given group of students during a given semester do not work as a very efficient team. Thirdly, this integration should never be attempted if all faculty involved do not firmly believe that they serve as role models for their students and, consequently, that they are, as far as their students are concerned, the most credible people when it come to competency development, whether these competencies are linked to science/technology or to the human dimension of engineering. Fourthly, and deriving from the preceding point, faculty involved should expect to go through some form of training for them to be able to play their role.

As stated earlier in this article, the ultimate result of our work would be to fully integrate to science/technology courses every aspect of the development of the competencies linked to the human dimension of engineering. Should this objective be achieved, the complementary studies courses would become redundant and could be done away with. This still appears to be possible but a lot of work has yet to be done.

\section{Bibliography}

[1] AL-HOLOU, Nizar et al_First-Year Integrated Curricula : Design Alternatives and Examples__ournal of Engineering Education, Oct. 1999, pp. 435-448.

[2] JOHANSSON, Conny, OHLSSON, Lennart_An Attempt to Teach Professionalism in Engineering Education_1994_http://www.hk-r.se/fou/forskinfo.nsf/35bc...ca

[3] SEAT, Elaine, LORD, Susan M. _Journal of Engineering Education, Oct. 1999, pp. 385-390

[4] GUNN, Craig James _ Creating the Spirit of Teamwork in the Freshmen Experience _ Proc. ASEE Annual conference, 2000

[5] WANKAT, Philip C., OREOVICZ, Frank S., ÉDELGASS, W. Nicholas_ Integrating Soft Criteria into the ChE Curriculum _Proc. ASEE Annual Conference, 2000

[6] SMITH, Karl A. Strategies for Developing Engineering Student's Teamwork and Project Management Skills_Proc. ASEE Annual Conference, 2000

[7] CLARK, Mark, MCMURCHIE, Donald _ Integrating Humanities and Engineering Technology Education Proc. ASEE Annual conference, 2001

[8] Mello, Natalie A. _ How Can Universities Provide a Global Perspectives for engineers? One Institution's Solution_Proc. ASEE Annual Conference, 2000

[9] Franklin W. Olin College of Engineering. http://www.olin.edu/academics/curric.html 
[10] Woods, D.R._New Approach for Developing Problem-solving Skills_ J. College Science Teaching, 23, pp 157-8, $199 \overline{3}$

[11] Woods, D.R. et al_Problem-based Learning: Helping Your Students Gain the Most From PBL, $3^{\text {rd }}$ edit., 1996, (http://www.chemeng.mcmaster.ca/pbl)

[12] LACHIVER, Gérard, DALLE, Daniel, BOUTIN, Noêl, THIBAULT, Richard, DIRAND, Jean-Marie, HIVON, René _ Redesign of Electrical and Computer Engineering Programs at Sherbrooke University _ Proceedings of the $12^{\text {th }}$ Canadian Conference on Engineering Education, Victoria, B.C., Canada, Aug. 2001

[13] LACHIVER, Gérard, DALLE, Daniel, BOUTIN, Noêl, DIRAND, Jean-Marie, THIBAULT, Richard, Implementing Competency-based Curricula in Electrical and Computer Engineering _ Proceeding of the SEFI Annual Conference _ Copenhagen, Sept. 2001

[14] BOUTIN, Noêl, THIBAULT, Richard, CLAVET, André, HADJOU, Brahim, DIRAND, Jean-Marie, MICHAUD, François, DALLE, Daniel, LACHIVER, Gérard _ Bringing First-year Engineering Students to Reflect on their Learning Strategies via a Learning Journal and an End-of-semester Essay in the Context of a Problem-based and Project-based Learning Curriculum_Proceedings of the ASEE Annual Conference, Montréal, Québec, Canada, May (June?) 2002

\section{RICHARD THIBAULT}

Richard Thibault is a full professor in the Department of Electrical and Computer Engineering, Université de Sherbrooke, Québec, Canada. He received his B.Eng.(Elec. Eng.) from the Université de Sherbrooke (1964), his Master's degree in Automatic Systems from the École Nationale Supérieure de l'Aéronautique in Paris, France (1965) and his Doctorate in Automatic Systems from the Université de Paris, France (1967). His fields of interest include engineering economics, the human dimension of engineering, engineering management, and program evaluation.

\section{NOÊL BOUTIN}

Noël Boutin is a professor in the Departement of Electrical and Computer Engineering at the Université de Sherbrooke, Québec, Canada. He received his B. Ing (1973) and his M.Sc.A. (1975) degrees in Electrical Engineering from the Université de Sherbrooke. His technical interests include RF circuit design and communication systems. His pedagogical interests include the development in undergraduate students of the competencies linked to the human dimension of engineering .

\section{DANIELLE L'HEUREUX}

Danielle L'Heureux is a project leader at the Institute of the Human Dimension in Engineering (IDHI) and a lecturer at Université de Sherbrooke, Québec (Canada). She received B.A. (1983) in Education at UQAT, Québec, Canada. Graduate from Université de Sherbrooke, she holds a M.A. (Ed.) (1994) and a Ph.D. (Ed.) (2000). Her main interests include the acquisition and the development of the personal and social competencies of Engineering students as well as the impact of cooperative training on university level education.

\section{RENÉ HIVON}

René Hivon received his B.Ped. (1963) and his Lic. Adm. Scol. (1966) from the Université de Montréal, Québec, Canada and his Doctorate (1969) from the Université de Caen, France. His main fields of interest are University Pedagogy, Pedagogy of Health Sciences, and Professional Expertise Development. While he is with the Faculty of Education, he participates in projects carried out in the School of Medicine, the School of Engineering and the School of Business Administration. 